\title{
UN MUNDO EN CAOS El desarrollo humano entre guerras, pobreza y crisis
}

Recibido: 01.06.2016 / Aprobado: 08.06.2016

\section{RESUMEN}

Julio Rodríguez y Nydia Castillo nos comparten una síntesis de su libro Tiempos de caos. Turbulencia y desarrollo de un mundo en crisis, donde se parte de la idea que el desarrollo humano constituye una opción integral orientada a crear un ámbito que les permita a los individuos sentirse integrados plenamente en las estructuras sociales, económicas y políticas. A la vez, se realza un derecho fundamental, el derecho a la paz.

Las guerras sin fin, crimen organizado, conflictos étnicos, exclusión y discriminación, altos índices de corrupción, desbordes sociales, luchas urbanas y campesinas, golpes de estado, atropellos a los derechos humanos, entre otros, conforman algunas de las tendencias que conducen hacia el caos. Aseveran que la expansión de fenómenos holísticos como la globalización y procesos desiguales de desarrollo amplían los abismos que separan cada vez más a pobres y ricos y a países desarrollados de otros que no lo son.

Palabras clave: Caos, desarrollo humano, desafíos sociales, oportunidades, vida digna.

\section{Introducción}

Patrocinado por universidades de México y Nicaragua se publicó, a fines del año 2015, el libro Tiempos de Caos. Turbulencias y desarrollo de un mundo en crisis, del que somos autores. Muy gentilmente, en 2016, el profesor Denis Torres y su equipo nos invitaron a presentar esta obra en la Universidad Politécnica de Nicaragua (UPOLI) y hacer una apretada síntesis para la revista Cultura de $\mathrm{Paz}$, de tan larga trayectoria y envergadura. Esto último
Por Julio Rodríguez Anido

Nydia María Castillo Pérez

\section{ABSTRACT}

Julio Rodriguez and Nydia Castillo share a summary of their book Times of chaos. Turbulence and development of a world in crisis. They emphasize on the idea that human development is a comprehensive option aimed at creating an environment that allows individuals to feel fully integrated into the social, economic and political structures. At the same time, they enhance a fundamental right, the right to peace.

Endless wars, organized crime, ethnic conflicts, exclusion and discrimination, high levels of corruption, social excesses, urban and peasant struggles, coups, human rights violations, among others, are some of the trends that lead to the chaos. They assert that the expansion of holistic phenomena such as globalization and uneven development processes widen the abyss separating increasingly rich and poor and other developed countries that are not.

Key words: Chaos, human development, social challenges, opportunities, dignified life.

1 Doctor en Sociología, Université du Québec a Montréal, Ph.D. Docente Investigador, Unidad Académica de Docencia Superior, Universidad Autónoma de Zacatecas, Miembro del Sistema Nacional de Investigadores, Perfil PROMPEP, México.

2 Doctora en Sociología, Universidad del Estado de Nueva York en Binghamton, Ph.D., Estados Unidos. Docente Investigadora, Unidad Académica de Docencia Superior, Universidad Autónoma de Zacatecas. Miembro del Sistema Nacional de Investigadores, Perfil PROMPEP, México. 


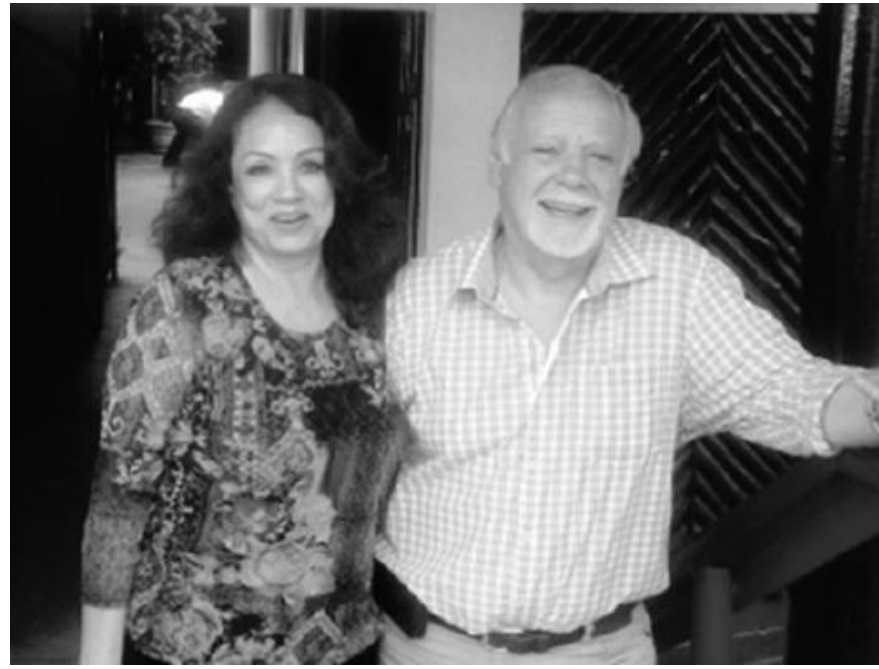

Dra. Nydia Castillo Pérez y Dr. Julio Rodríguez Anido.

justa distribución de la riqueza, son condiciones básicas de ese Modelo, junto con el libre flujo informativo y la adquisición de conocimientos (Calderón, F.; 2006; Sen, A.; 2007).

Ese concepto de desarrollo prioriza la capacidad de ofrecer a las personas la posibilidad de elegir, entre diversas alternativas, aquellas que ellas mismas consideren como más valiosas para lograr su desarrollo integral. A la vez, se realza un derecho fundamental, el derecho a la paz. Se hace así referencia a las oportunidades que deben tener los individuos de lograr una vida larga, saludable, acceder a conocimientos individuales y sentirse socialmente útiles por estar involucrados, en plenitud, en las actividades de su entorno social y político (PNUD (2012).

Redimensionar el concepto de desarrollo humano conlleva la revisión de algunos aportes teóricos que parten del impacto que producen las políticas públicas actuales imperantes en el mundo, de neto corte neoliberal. Igualmente, a explicar los problemas estructurales que condicionan las instituciones y hacen pensar que estas parecen haber perdido la capacidad de asegurar la distribución de la riqueza en función del desarrollo social y cultural de los individuos y las naciones.

En efecto, vivimos un mundo en el cual guerras sin fin, crimen organizado, conflictos étnicos con secuelas de xenofobia, exclusión y discriminación, altos índices de corrupción en gobiernos e instituciones, desbordes sociales, nuevos tipos de formas mortíferas de guerrilla, luchas urbanas y campesinas, golpes de estado, atropellos a los derechos humanos, asesinatos masivos de poblaciones atrapadas en torbellinos de violencia, tortura de prisioneros, desaparición de personas, sociedades cada vez menos libres, degradación del medio ambiente y decaimiento de la biodiversidad, conforman algunas de las tendencias que se propagan en ese deslizar hacia el caos. Todo ello suscita un enjambre de desafíos sociales que contribuyen a configurar el Siglo de la Incertidumbre que vivimos donde florecen autoritarismos $y$ se agudizan fenómenos endémicos que no reconocen fronteras nacionales como pobreza, pobreza extrema, grandes migraciones humanas, $\neg$ que configuran éxodos apocalípticos, y descontrol del incremento poblacional. En inmensas regiones del planeta, esa problemática viene acompañada por el hambre, el ébola y el Sida.

En la tierra que nos cobija, cada vez más pequeña, participamos de la expansión de fenómenos holísticos como la globalización y en procesos desiguales de desarrollo que amplían los abismos que separan cada vez más a pobres y ricos y a países desarrollados de otros que no lo son.

A medida que el sistema capitalista profundiza su fase neo-liberal y con él, la Modernidad toda se desintegra, pareciera que nos encontráramos inmersos en un momento mayor de transición, el paso de un modo de producción a otro, cuyas formas principales aún no conocemos. Las relaciones capitalistas de producción - que históricamente han girado alrededor de la oposición entre capital y proletariado - podrían ceder paso a formas distintas de organización económica

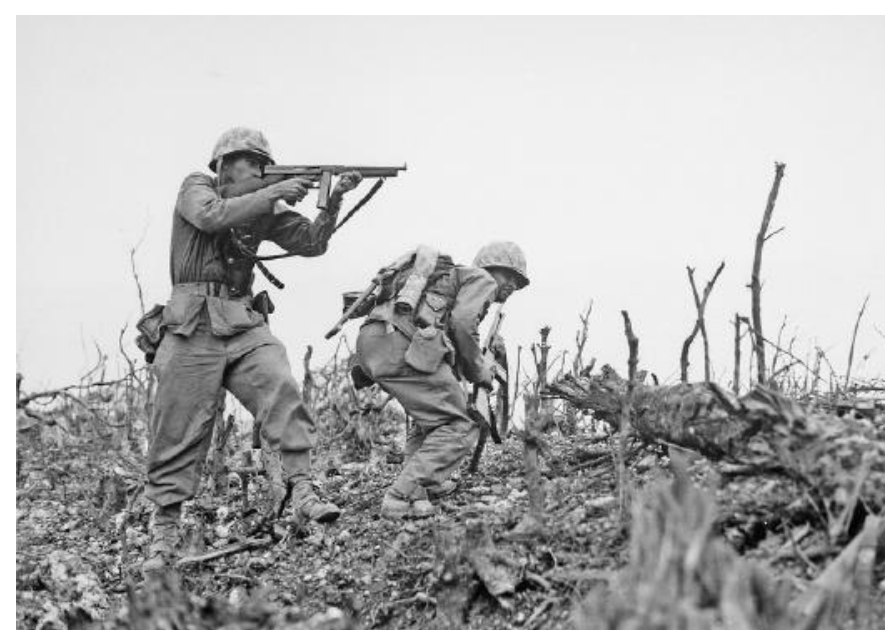


y social todavía incipientes. Eso ocurre en momentos que las sociedades civiles y políticas del mundo sufren la presión de tremendos procesos de cambio impulsados por fuerzas económicas, financieras, sociales, políticas y hecho nuevo, religiosas, globales, de gran envergadura.

Del caos parece surgir la transición hacia formas inéditas de cultura y el advenimiento de una nueva era. Si así fuera, esas tendencias concretizarán un momento crucial de la historia humana en los que las transformaciones de diferente naturaleza se precipitan, entremezclan y producen un cúmulo de cambios de distinto orden. En nuestro caso, se encuentran facilitadas por el advenimiento de la globalización y la sociedad del conocimiento, fenómenos que irrumpen en el mundo convocación de renovar las sociedades, para bien o para mal, en todos sus aspectos.

Es precisamente a través de esas cuestiones que tratamos de visualizar el espacio que queda para el desarrollo humano enfrentado a tendencias mayores que están cambiando el sentido mismo del concepto de desarrollo del mundo complejo, caótico, que vivimos. El gran desorden global existente no permite hablar más de desarrollo como algo unívoco, que valga para todos. No es lo mismo verlo desde estados pobres que de estados ricos, ni hacer abstracción de las diferencias sociales - abismos en algunos caso - que hacen que haya en el mundo cerca de mil millones de personas que no tienen acceso, ni siquiera, al agua potable.

Los enfoques teóricos difieren enormemente. Ellos dependen de los países y las clases sociales en las que los autores están insertos, de las tendencias que inspiran las políticas públicas, de las orientaciones de los sectores privados y los puntos de vista que se esgrimen en conferencias nacionales e internacionales donde prevalecen las relaciones de fuerza que expresan intereses diferentes, normalmente contradictorios.

Esas oposiciones se agudizan por el hecho de transitar un siglo calificado de incertidumbre, por ser "...una nueva época más que un siglo; una época de transición donde los cambios serán inacabados e impredecibles..." ya que “... este siglo se adelantó a su

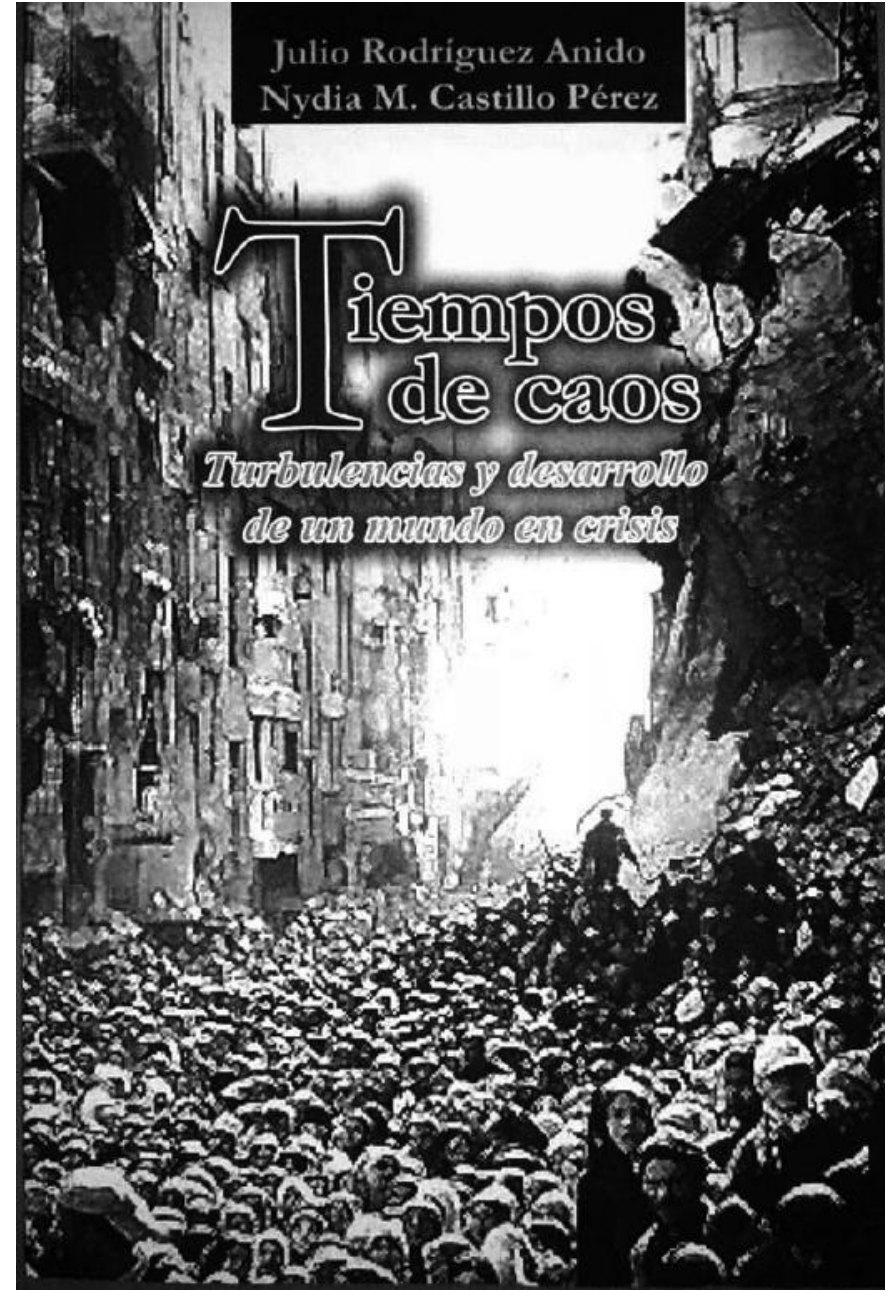

propio tiempo y apenas estamos empezando a sentir los efectos de la nueva racionalidad..." (Miguel Ángel Escotet; 2003). En él, el universalismo pregonado por los beneficiarios y los sostenedores de la globalización, es reemplazado por el más crudo nacionalismo xenofóbico y excluyente y las ideas de cambio aparecen frecuentemente, lo que es paradojal, en el discurso de quienes sostienen intereses económicos, financieros o políticos particulares y excluyentes, lo que se concretiza a través de la adopción y práctica de políticas neoliberales cada vez más disfuncionales.

En efecto, los discursos de Donald Trump, ${ }^{3}$ candidato a presidente de Estados Unidos en el proceso preelectoral de 2015 y de Jean-Marie Le Pen, ${ }^{4}$ en ocasión de los comicios celebrados en diciembre de ese mismo año en Francia, son extremadamente ilustrativos sobre

3 El discurso de este precandidato Republicano a la presidencia de Estados Unidos opera en base al miedo, la xenofobia y los procesos de exclusión.

4 Le Pen, y su hija, que recibió el partido fundado por su padre como herencia, representa una fracción de la sociedad francesa que se caracteriza por la violencia extremista y el auto centrismo. 


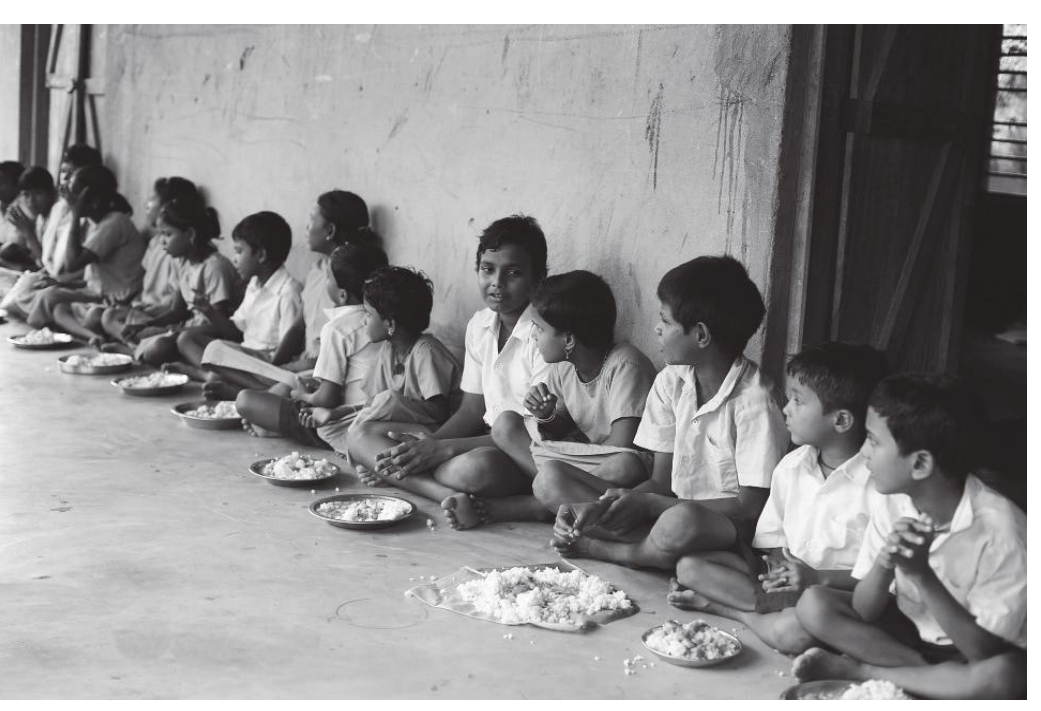

ese tema particular. Este siglo, nos hace penetrar en una dimensión distinta, en una nueva sociedad, donde un gran caos, como destaca (Ignacio Ramonet; 1999), nos rodea. De allí que Jacquard y Lacarriè, señalen que “... los descubrimientos realizados después de medio siglo nos permiten ver al mundo de manera extremadamente distinta de lo que se podía pensar todavía hace cincuenta años..." Y que agreguen: "...en el siglo XX, todo ha cambiado: la materia, el tiempo...los conceptos..."... la ciencia y la técnica han sufrido cambios extraordinarios en poco espacio de tiempo..."

Es así como se transforman los conceptos de tiempo, espacio, percepciones y maneras de pensar en la sociedad científica y tecnológica globalizada que hace trastabillar concepciones arraigadas en el inconsciente colectivo sobre Estado, Nación y Derecho (Albert Jacquard y Jacques Lacarrière; 1999). La electrónica, por su parte, empujada por la ciencia y la tecnología, transporta al mundo a la era de la cyber-economía, los ordenadores personales se expanden por doquier y se multiplican las redes que los interconectan (Stéphanie Bonvicini y Jacques Attali; 2009). En una sociedad tan diferente de las anteriores, el ciudadano y el Estado encuentran grandes dificultades para construir sus propios espacios; sus brújulas giran en espacios virtuales mayores transformados en territorios por conquistar. ${ }^{5}$ Veamos algunas de esas cuestiones más en detalle.

\section{Guerras y religiones; abismos de violencia}

En 2016, otra vez, el escenario está preparado. Luego de los sangrientos atentados perpetrados en 2001 en Nueva York; en 2002, en Madrid; en 2005, en Londres, en otras capitales del mundo en distintas fechas; en 2015, en Paris y San Bernardino, California, Estados Unidos y Niza; en 2016, la gente espera ver en sus televisores un gran espectáculo, una nueva guerra, por despiadada que sea. Esa actitud es similar a la que se tuvo en ocasión de la "Tempestad sobre el desierto", como se llamó a la guerra desatada por George Bush en 1991 - por ese entonces presidente de Estados Unidos - , contra el estado de Irak, dirigido por Sadam Hussein. O bien, como ocurrió en ocasión de "... la primera guerra del siglo XXI...que está comenzando..." (J. Rodríguez Anido, La Feria de las Maravillas; 2007), según dijo. refiriéndose a ese nuevo conflicto internacional su hijo, George W. Bush, el guerrero ex presidente de Estados Unidos cuando la iniciara"...para acabar con armas de destrucción masiva..." que no existieron jamás. Este último, continuaba la tarea de aquel otro que al término de la "Tempestad sobre el Desierto" proclamó a los cuatro vientos: "... se inicia un nuevo orden mundial... (La Tribune, “Un monde qui se bouleverse"; 2001)".

La pregunta, hoy como ayer, es la siguiente: ¿Se trata de un conflicto puntual, una nueva confrontación entre bandos enemigos, uno de los cuales ha llevado a cabo ataques a traición, cometiendo nuevos "Pearl Harbor", al golpear sin previo aviso los centros del poder financiero y militar de los principales países industrializados incluyendo Gran Bretaña, España, Francia y Estados Unidos? La experiencia y la memoria histórica indican que se ha iniciado más bien una nueva etapa de un conflicto mundial que ya lleva más de sesenta años de duración, comenzado con la Guerra Fría - el enfrentamiento entre la ex-Unión Soviética y sus aliados con Estados Unidos y los llamados "países civilizados" a pesar que, según se proclamó en los años 1990, había llegaba a su fin. Ese conflicto, Originado cuando concluía la segunda Guerra Mundial e inspirado por la posesión

5 En la Sociedad del Conocimiento, en tiempos de globalización, luego de un siglo de gigantesco desarrollo tecnológico, el foso que separa las clases sociales y los países entre sí, a comienzos del siglo XXI, se ahonda. La humanidad se halla embarcada en procesos de transformaciones radicales cuyas metas finales son imprevisibles. 


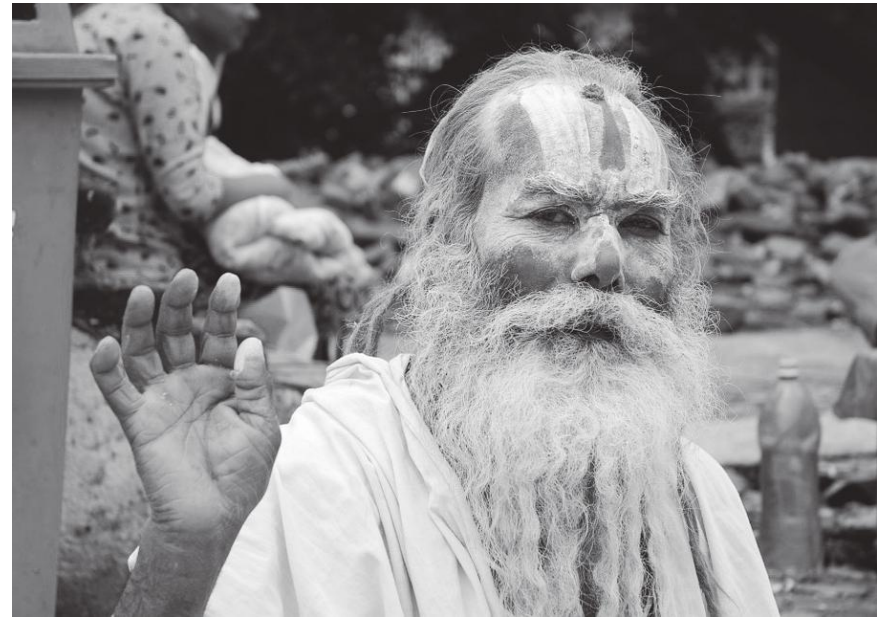

de recursos disponibles en terceros países, dividió al mundo ${ }^{6}$ en bandos antagónicos.

El origen más inmediato de los enfrentamientos actuales remonta a fines de los años 1970 cuando contradicciones originadas en la disputa por territorio petroleros-transformadas en confrontaciones armadas - dividieron a Estados Unidos y sus aliados de los países árabes y musulmanes, especialmente aquellos situados en el Medio Oriente. Con el tiempo, se extendió hasta los confines del mundo Indio abarcando pueblos islámicos de Asia y África, nuevos adversarios de los estados industrializados que como por azar, cuentan con las mayores reservas mundiales de petróleo. La toma de rehenes por estudiantes iraníes en 1978, luego de la caída del régimen despótico de Mohamed Reza Pahlevi, que Estados Unidos sostuvo hasta el fin - durante el gobierno de Jimmy Carter - y la intervención norteamericana en la guerra librada entre los soviéticos y el pueblo de Afganistán desde 1979, constituyen jalones sucesivos de ese conflicto global.

A comienzos de los años 80, Ronald Reagan, "el gran comunicador", ex presidente de los Estados Unidos - que en abril de 1986 hizo bombardear Libia, otro país musulmán-, llamó "luchadores por la libertad" a las fuerzas dirigidas por Osama Bin Laden, a quien la CIA enseñó las técnicas terroristas más sofisticadas durante la guerra de Afganistán contra Rusia. El millonario
Saudita, por su parte, combinó ese nuevo saber con el fundamentalismo musulmán para dirigirlas contra los propios Estados Unidos desde que rompe con los norteamericanos cuando éstos destruyen Irak durante la Guerra del Golfo, No les perdonaba que hubieran instalado gran parte de su maquinaria de guerra en la tierra Santa de La Meca y Medina. Desde entonces, Bin Laden, al igual que el Hezbolá libanés y el Hamás palestino, combinaron técnicas norteamericanas con el fanatismo de los desesperados de los campos de refugiados y los suburbios pobres del norte de África y Oriente Próximo. Al fin de la Guerra del Golfo, el combate entre Israel y el pueblo palestino, apoyado por el mundo árabe e islámico, se intensifica.

El recrudecimiento de la dominación del régimen sionista sobre Palestina se incrementa conllevando la destrucción de hogares, implantación de nuevas colonias judías de población, asesinato de dirigentes palestinos y otros actos de terrorismo de estado que llevan a las Intifadas (levantamientos del pueblo palestino) ${ }^{7}$. En 1998, como respuesta a los atentados terroristas contra dos de sus embajadas en África, el presidente Bill Clinton, de estados Unidos, elige dos lugares para bombardear a distancia (La Tribune, "Un monde qui se bouleverse"; 1998): Un campamento de Bin Laden en Afganistán y una fábrica próxima a Jartum, Sudán, donde según la CIA, se fabricaban armas químicas cuando solo se trataba de una fábrica de productos farmacéuticos que trabajaba con organizaciones humanitarias internacionales.

La guerra entre Estados Unidos y el mundo musulmán adquiere nuevas modalidades; se decía que Bin Laden planeaba ataques con armas químicas, biológicas y nucleares y que sus seguidores actúan en la sombra integrando un pequeño -y muy eficaz - ejército, cuyos componentes provienen de los cuatro rincones del mundo árabe y musulmán; son argelinos, tunecinos, palestinos, sirios, libaneses, afganos, sudaneses, yemenitas o iraníes. Muchos vivían en Estados Unidos, protegidos por sus profesiones de informáticos, ingenieros, pilotos de aviones o médicos. Todos estaban dispuestos a morir en la lucha contra el Imperio.

6 A gran escala, se alineó dentro de la línea histórica de comportamiento de las potencias imperiales solo que esa guerra no fue tan "fría"; la violencia transitó campos de batalla en África, Asia y América Latina. El orden mundial que siguió permitió a los países ricos imponer sus leyes al mundo en tiempos modernos de la globalización.

7 La Banda de Gaza y Cisjordania son escenarios constantes de confrontaciones que arrojan miles de víctimas y cuantiosos daños materiales. Israel siempre contó con la ayuda de Estados Unidos, el Reino Unido y otros países europeos. 
La primera guerra del siglo XXI no era algo nuevo: Pero resultaba inusitado su nivel de violencia, sofisticación y la capacidad de los guerreros musulmanes para alcanzar objetivos en el corazón de Estados Unidos y de grandes potencias industriales $y$ militares como Francia e Inglaterra. En ese proceso, Arabia Saudita ha sido siempre un aliado árabe privilegiado por Estados Unidos ${ }^{8} \quad$ Sin embargo, los atentados del 11de Septiembre de 2001 contra ese país mostraron que de los 19 terroristas que participaron de las acciones, 15 eran originarios de ese país aliado9. Arabia Saudita es reconocido como cuna del Islam. Allí es donde los musulmanes deben ir a orar al menos una vez en la vida y en cuya dirección se arrodillan cinco veces al día sin que importe el lugar del mundo donde se encuentren. Y la guerra se extendió de Israel y Palestina a Afganistán, Irak, Yemen, Pakistán, Sudán, Somalia, Etiopía, Congo, y otras vastas regiones de Asia y África.

Hubo incluso quienes imaginan un combate entre Occidente y el Islam, sin pensar que este último constituye una gran civilización desarrollada en simbiosis con una religión que practican más de mil quinientos millones de personas en el mundo. Sin embargo, hoy aparece virulento, tanto o más que otras civilizaciones como la Budista o la Hinduista que juntas, reagrupan a tres mil millones de personas. Ello ocurre porque dentro del Islam han emergido ramas "fundamentalistas", Al Qaeda, que aspira a controlar los Estados nacionales musulmanes e ISIS que no propone reflexión alguna, teológica, o de naturaleza social; su objetivo fijo es la toma del poder en el orden internacional. Ambos ejércitos retienen costumbres $-\mathrm{y}$ rituales musulmanes - , a las que exigen respeto absoluto. Esas vertientes del Islam combaten al régimen Saudita y otros estados del Golfo, profundamente corrompidos, que disfrutan de enormes riquezas en medio de pueblos pobres.

La expansión de $\mathrm{Al}$ Qaeda, la muerte de Bin Laden, la aparición del ISIS, estado musulmán que sus adeptos llaman Califato, enclavado entre Irak y Siria, al que confluyen militantes y mercenarios de todo el mundo, incluyendo Estados Unidos, Inglaterra y América Latina, incrementa la guerra civil estallada en Siria al mismo tiempo que se extienden guerras internacionales en suelo Iraquí, Afgano y de Paquistán, de la que participan directa o indirectamente Rusia y Estados Unidos, que se amplían luego del ataque terrorista, a fines de2015, en París, San Bernardino, en California y en 2016, en Niza, Francia. El miedo se reinstala en Estados Unidos, esta vez también en Francia, ya no contra las armas biológicas, como en 2001, sino a los ataques suicidas de militantes musulmanes. Francia se une a los bombardeos rusos y estadounidenses en suelo sirio e iraquí; a inicios de 2016, ya eran sesenta y cinco países los que participaban en esa conflagración. El Papa Francisco, jefe de la iglesia católica, previene a la humanidad que se halla a las puertas de una Tercera Guerra Mundial ${ }^{10}$ de la que no está excluida, ni siquiera, la Santa Sede ${ }^{11}$.

El caos pasa también por las organizaciones económicas extendiéndose a las estructuras políticas y sociales; el desorden se disemina y transfiere de un país al otro. En América Latina, estremece el triángulo norte de América Central, Guatemala, Salvador y

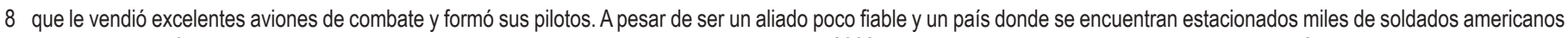
listos para su defensa, Abdalá Ben Abdelaziz, el príncipe heredero, sorprendió al mundo en 2002 al enunciar un nuevo plan de paz para el Medio Oriente

9 En realidad, Abdelazis no se comportaba como su antecesor, el rey Fahd, un aliado dócil de Estados Unidos que murió en 1995, víctima de un ataque cerebral.

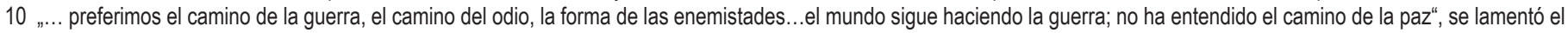
Sumo Pontífice. La Gaceta, 19.11.15.

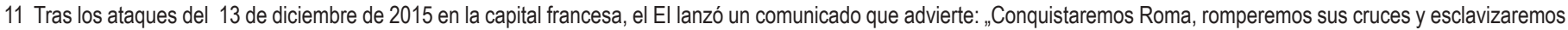
a sus mujeres, con el permiso de Alá, el elevado..." 


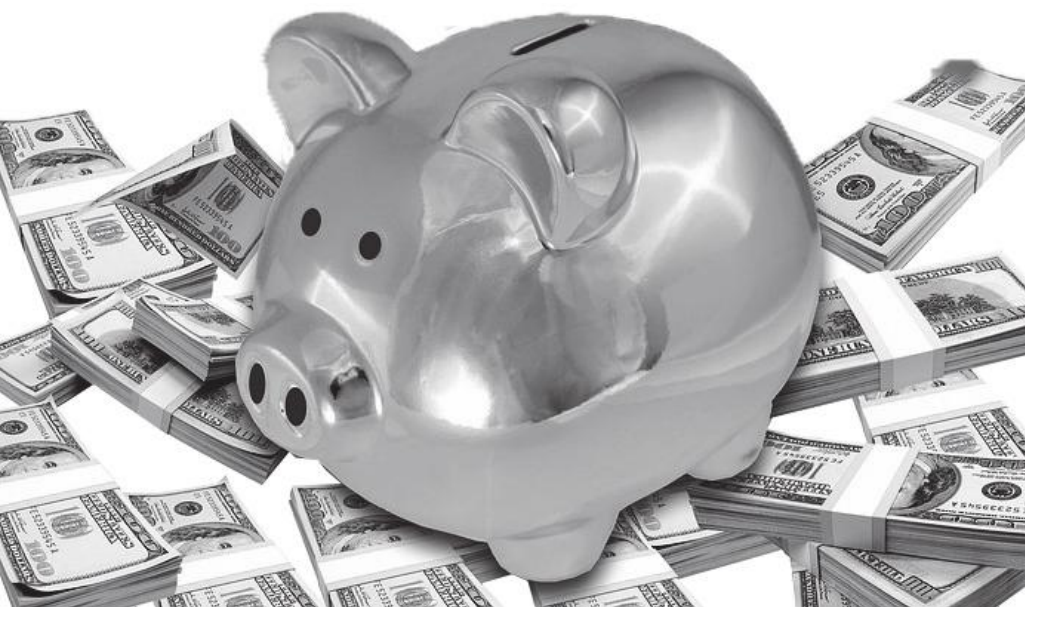

Honduras, países atrapados en espirales de violencia arrastrando tras de sí a instituciones sociales y políticas. Al incrementarse el miedo, el hambre y la emigración masiva de las poblaciones, los conflictos y la violencia se repercuten sobre los modelos de desarrollo del mundo, especialmente cuando la industria armamentista está más próspera que nunca. La venta y contrabando de armas no se limita a los países en guerra, sirven para alentar el accionar de bandas delincuenciales; es el caso de México, según lo reveló la operación "Rápido y furioso". Las características y matices de los procesos de desarrollo en un mundo en caos y las prioridades que retienen los estados en contextos de represión, guerra, violencia y pobreza, son distintas de lo que él implica de acuerdo a su naturaleza. El desarrollo de las naciones necesita el orden y la paz.

\section{Fragilidad de las estructuras económicas y financieras}

Las fracturas hoy aparecen a ojos vista. Se perciben las fallas de los modelos de desarrollo en vigor por ser tributarios de orientaciones económicas mayores y por ajustarse y reajustarse en función de la correlación de fuerzas existentes. Ellas imponen un discurso casi monolítico. La tendencia va en el sentido de racionalizar políticas neoliberales, ultra liberales, fundadas en la creencia de la eficacia absoluta de los mercados sin constituir doctrina o teoría económica. Hacen parte de una ideología, ni siquiera una doctrina o una teoría económica, que se apoya sobre una visión de la economía percibida como mecanismo que obedece a leyes naturales que los economistas sacan a la luz, como los físicos lo hacen con la naturaleza. Así, el discurso económico dominante hace parte de una ideología de la responsabilidad individual; las obligaciones colectivas son garantes de la capacidad de los individuos de ejercer su libertad, con lo que se legitima el orden estatuido, algo que se debe conservar a todo precio.

Sostiene que la interacción libera de todo condicionamiento a los individuos y cada uno percibe sus intereses egoístas como algo capaz de generar el máximo bienestar posible para el conjunto de la colectividad; es en el mercado donde ese prodigio se opera. El estado no debe intervenir en la economía, ofrecer servicios públicos o realizar transferencias a los sectores sociales, sin privatizar las actividades económicas y financieras excluya a las subvenciones a las empresas y el aumento de los gastos militares.

Como consecuencia, las grandes transformaciones económicas y financieras sucedidas desde inicios de la Revolución Industrial, a fines del siglo XX, desembocan en el control del mundo por parte del capital financiero. Dominados por las finanzas, los estados imponen en el siglo XXI esa forma capitalista de producción y consumo a prácticamente todos los sistemas económicos del planeta ( $E l$ Sol de Zacatecas, "Un mundo en cambio"; 2007). Como resultado, la crisis económica actual es también la de los sistemas políticos y sociales del mundo. Con ella, entran también en crisis los modelos de desarrollo que mantienen y expanden ese ordenamiento.

Frente a la desaceleración y el estancamiento económico, Boltvinik Kalinka señala que el estancamiento económico mundial que ocurre desde la iniciación de la crisis económico-financiera mundial de 2008, hace referencia al estado económico permanente del capitalismo contemporáneo. Ese explica varios autores, como"... unacrisis sinfin, porqueinfluyeinexorablemente en el funcionamiento de lo que llamamos el capitalismo monopolista financiero, dominado por un puñado de corporaciones gigantes..."12. Si el capitalismo ya no crece es posiblemente porque se halla en situación agónica. No se trata solo de una crisis de la economía capitalista; también lo es de la propia ciencia económica ortodoxa.

12 Martín Catalán Lerma, "La salvación del planeta pasa por trascender del capitalismo", citando a Julio Boltvinik Kalinka, del Centro de Estudios Sociológicos de El Colegio de México, La Jornada, Zacatecas 06.06.15. 


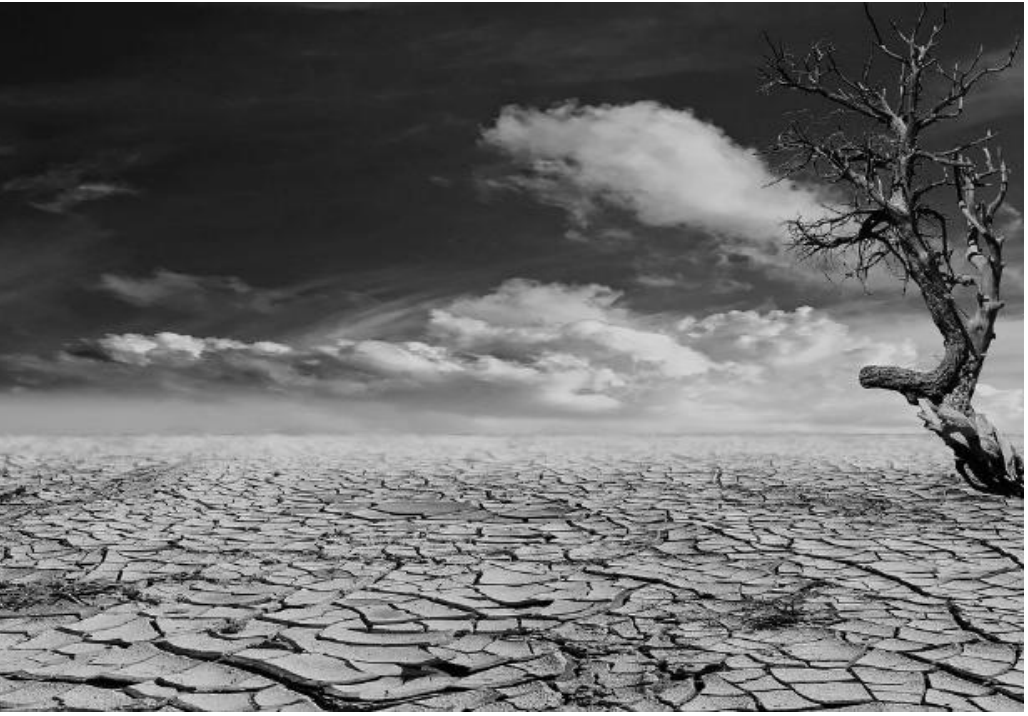

La actual crisis mayor de orden estructural conduce inexorablemente a la crisis alimentaria mundial como consecuencia del agotamiento del modelo de agricultura contaminante, cuyo rendimiento se ha estancado. En países como Estados Unidos, ese sector productivo representa 3 por ciento del PIB, “... pero hay economistas que dicen que puede bajarse a cero y no pasaría nada a la economía norteamericana. No entienden que hay de mercancías a mercancías y que los alimentos no son como cualquiera, porque de ellos depende la vida..."13. Se produce igualmente el desmantelamiento de la sociedad centrada en el trabajo pagado, fenómeno cada vez más presente en la actualidad; la automatización generalizada de los procesos productivos disminuye a tal grado la participación del trabajo manual e intelectual, que la sociedad basada en el trabajo asalariado ya no puede funcionar sin cambios radicales. Además, la creciente concentración de la riqueza es un factor que se incentiva en el capitalismo de las últimas décadas.

\section{Sobrepoblación, escasez de agua, fin de la civilización del petróleo}

El planeta alcanzó los primeros mil millones de habitantes luego de millares de años de existencia de la vida humana. Para llegar a los dos mil millones, se necesitaron ciento veintitrés años; sólo debieron transcurrir once años para pasar de cinco mil a seis mil millones. Si la humanidad estabilizara su crecimiento en $2.1 \%$ en el curso del presente siglo, la población mundial alcanzaría los 8,400 millones en el 2030, para estabilizarse en torno a 10 mil millones de personas ${ }^{14}$. Siguiendo el ritmo de cambios tan substanciales, la civilización occidental se torna cada vez más urbana y aparecen interrogantes sobre cómo serán las ciudades superpobladas del tercer milenio, cuando terminen de transformarse radicalmente, luego de ser, en el pasado, el lugar del mercado, la feria con animales, el lugar de concentración e intercambio de la moneda y después, el sitio donde se crea el empleo para el campo que lo rodea, o bien, la mina o la fábrica ${ }^{15}$. Al ritmo actual de urbanización, las ciudades que más rápido crecen, en conjunto, reciben 616 personas por hora y por ello, el futuro se presenta cargado de problemas ligados a la urbanización acelerada ${ }^{16}$.

Al mismo tiempo que se agudiza el fenómeno de la superpoblación, el agua potable, elemento esencial para la existencia de la vida, se transforma en uno de los recursos más raros y codiciados; pronto, puede llegar a provocar guerras. Si hacemos girar un globo terrestre, nuestro mundo parece rebosar de una infinita cantidad de agua ${ }^{17}$, pero Nadine Gordimer señala que no es sorprendente que los recursos de agua sean causa de conflicto entre comunidades y territorios ${ }^{18}$. Así, la agricultura utiliza actualmente los dos tercios del agua potable y la superficie regada debería aumentó en 2010,

\footnotetext{
13 Martín Catalán Lerma, op. cit.

14 Esa concentración urbana hará emerger nuevos problemas, mismos que constituyen desafíos de impacto para urbanistas, arquitectos, políticos, economistas, sociólogos, antropólogos y muchos especialistas más.

15 Según la Organización de las Naciones Unidas (ONU), en el año 2015 hay 33 megalópolis, de las cuales 27 están en países subdesarrollados.

16 Que viene acompañado con una cohorte de violencia urbana, contaminación, proliferación de asentamientos precarios, saturación habitacional, sanitaria y de infraestructuras y finalmente, el hambre, creando verdaderas montañas basura y muchos otros flagelos que forman parte de la vida cotidiana de las urbes

17 Aunque el $70 \%$ de la superficie de la Tierra está cubierta de agua, el $97.5 \%$ de esa agua es salada. Del $2.5 \%$ restante, el agua fresca de la que depende la sociedad humana, casi tres cuartas partes están congeladas.

18 Nadine Gordimer, Premio Nobel, en un artículo publicado en The New York Times, reproducido por La Nación, 2003, p. 5, señala: "...la necesidad exige que el agua sea compartida para asegurar la supervivencia de todos... El consumo de agua creció el doble que el porcentaje de crecimiento de la población mundial. 2 millones y medio de personas mueren cada año por enfermedades provocadas por impurezas del agua. Mueren 6000 niños por día por la misma causa..."
} 
en un tercio y lo hará en $50 \%$, para 2025 , con miras a satisfacer la demanda alimentaria siguiendo los niveles actuales.

El uso industrial y doméstico de agua crecerá a un ritmo diez veces superior al de la población: la demanda se duplicará cada veinte años, sin que la oferta registre cambios; el $97 \%$ de las aguas del planeta son saladas y del $3 \%$ de las probables, los dos tercios se hallan en Groenlandia y el Antártico, o flotan como témpanos.

Por otra parte, la contaminación reducirá aún más la cantidad de agua disponible, su precio subirá enormemente, aumentará el control de su uso industrial y privado y a la par, se desarrollarán técnicas de desalinización del agua de mar. Tal problemática incluye el mal cuidado del aire, recurso terriblemente amenazado por la contaminación industrial y urbana; se transformará también en algo raro y costoso.

Solo una quinta parte de la población mundial respira un aire aceptable, ${ }^{19}$ los países del Norte utilizan el $70 \%$ de los vehículos que circulan en el mundo y producen el $60 \%$ de los residuos de carbono y óxido nítrico ${ }^{20}$. Hoy se producen 30 millones de vehículos, cantidad que puede doblarse rápidamente. Si así fuera, pronto habrá 1000 millones de vehículos en servicio, en lugar de los 800 millones existentes. Eso puede producir efectos desastrosos sobre el aire, la reducción de las tierras agrícolas disponibles y caos urbano ${ }^{21}$.

Se ha conformado así la civilización del petróleo "que vivimos, heredada de la Revolución Industrial, iniciada a fines del siglo XVIII y comienzos del XIX, que significó la sustitución del empleo de la tracción animal por máquinas movidas por combustibles de origen fósil - primero, el carbón mineral y luego, el petróleo y el gas natural - “22. Las enormes masas de dinero involucradas explican la fuerza y subsistencia de la civilización del petróleo, pero preanuncian la necesidad de desplegar enormes esfuerzos de creatividad para lograr su reemplazo puesto que la cuenta regresiva se ha acelerado dramáticamente desde hace algo más de medio siglo. Dentro de 40 o 50 años, llegará inexorablemente a su fin. De allí que los modelos de desarrollo contemplen

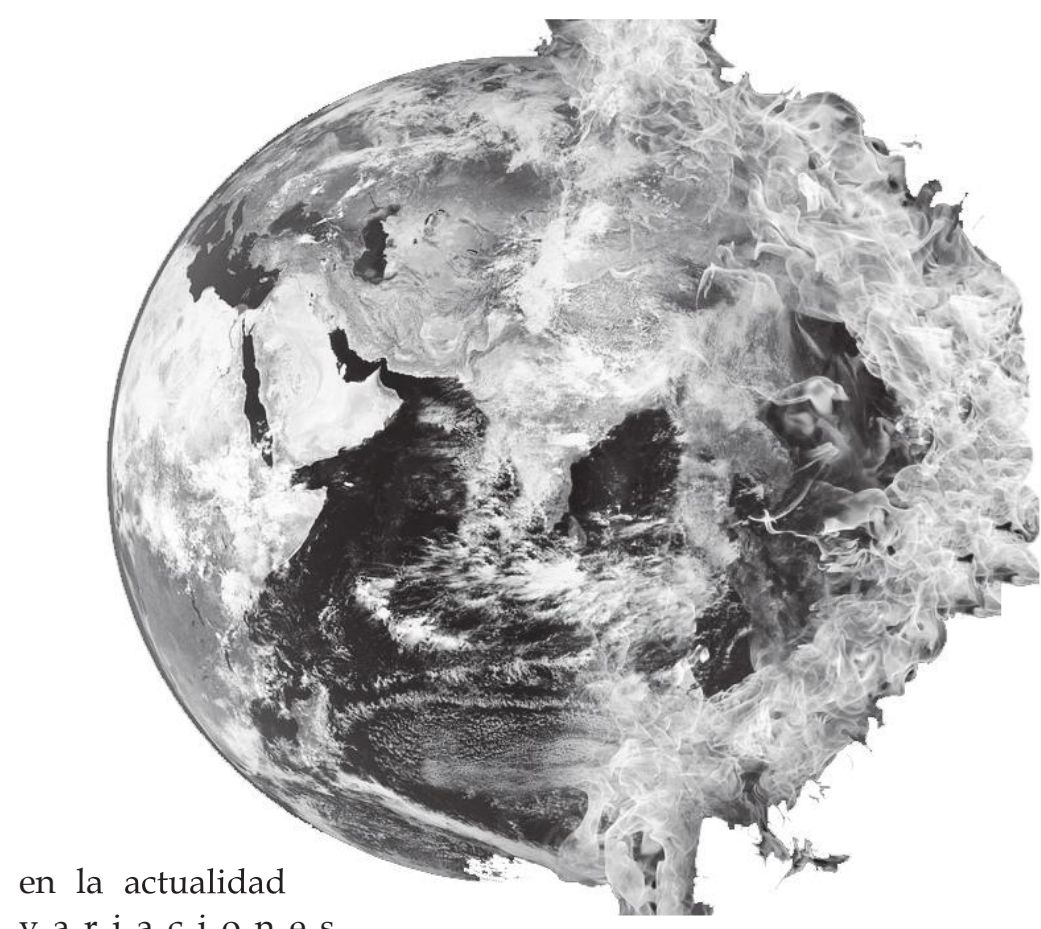

$\mathrm{v}$ a r i a c i o $\mathrm{nes}$

fundamentales en materia de

provisión de energía influyendo poderosamente en la forma de encarar la vida económica y social presente y futura; la fuente de energía no renovable que moldeó la historia del siglo XX y cuyo fin ineludible emerge a ojos vista, coloca a la humanidad en una carrera contra el tiempo. Los países industrializados y otros que no lo son pero que lo necesitan, buscan sustitutos para el "oro negro". De las decisiones que se adopten en esa materia, dependerá el futuro de la humanidad toda. En el mundo se está considerando seriamente que se aproxima ese fin y se evalúan sus terribles consecuencias.

A pesar que los países tratan de prepararse y que se sepa que cada vez más habrá menos petróleo, en el planeta se consume diariamente, unos 90 millones de barriles de petróleo. Al ritmo actual de extracción, puede durar entre 40 y 60 años. Estamos cerca del "peak de petróleo"; el punto de partida desde el cual la producción comenzará a decaer hasta desaparecer completamente. No resulta casual que en el reemplazo del petróleo los países industrializados aboguen por

19 El aire de los países del Sur es menos puro que el del Norte: el de Pekín es 35 veces menos respirable que el de Londres, y 16 veces menos que el de Tokio.

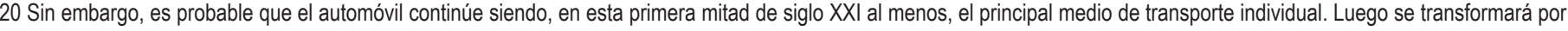
completo; probablemente será prohibido en las ciudades.

21 En ese contexto, el arte de construir será modificado. Al transformarse el mundo urbano, habrá cambios sustanciales en arquitectura.

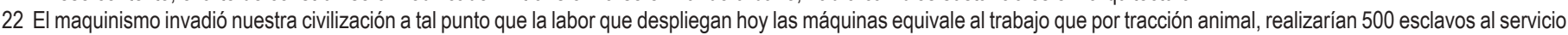
de cada uno de nosotros. Al mismo tiempo, se puede calcular el valor de la caloría de un asalariado que percibe un sueldo mensual y comparar dicho valor con el de la caloría del petróleo a precios actuales. En tal caso, la caloría del petróleo resulta ser unas 500 veces más barata que la humana. 
incrementar la producción de biocombustibles, basados en concepciones económicas, políticas y ecológicas. Sus líderes saben que los años del petróleo barato son historia ${ }^{23}$.

Quienes apuestan al futuro de los combustibles vegetales afirman que se convertirán en un protagonistas de talla de la próxima revolución energética y que en función de ellos, se rediseñará el mapa geopolítico del mundo. Esas fuentes de energía se convertirían, aunque pocos lo creen, en fuentes no contaminantes de energía. Las posibilidades parecen ser ilimitadas, pero resuenen alarmas justificadas que cuestionan el uso de alimentos como combustibles ${ }^{24}$. Hasta los más optimistas saben que la era de los biocombustibles, si algún día se convierte en realidad, aún da sus primeros pasos ${ }^{25}$.

\section{Medio ambiente, biodiversidad, migraciones humanas: un gran desorden}

Cuando el Protocolo de Kioto expiró y después de pasar por el fracaso de la reunión de Copenhague de 2009, cerca de 200 países del mundo, más de 150 jefes de estado y de gobierno se reunieron en París, a fines de 2015, para concertar a los Estados que forman parte de la Convención Marco de las Naciones Unidas sobre el Cambio Climático (CMNUCCI) y mejorar la cooperación a efectos de limitar el aumento de la temperatura media global en $2^{\circ} \mathrm{C}$ por encima de los niveles preindustriales. Adicionalmente, los países estaban invitados a presentar sus contribuciones previstas y determinadas a nivel nacional de manera voluntaria, sin efectos sobre la negociación principal. La apuesta era alta. Urgía llegar a un acuerdo sobre la forma de reducir las emisiones de gases de efecto invernadero y acordar la manera cómo los países más afectados por este fenómeno pueden adaptarse al aumento del nivel del agua y la desertificación.
Dos temas arriesgaron el fracaso de la conferencia, el apoyo financiero a los países del Sur y la distribución de la carga financiera entre los países desarrollados y en vías de desarrollo. Los escollos fueron salvados; los acuerdos, firmados. Sin embargo, gran parte de la problemática ligada a la deterioración y destrucción del medio ambiente y la contaminación ambiental carbono solo es una parte de grandes tendencias que llevan al hombre a destruir su propia casa ${ }^{26}$.

Ya la convención organizada por

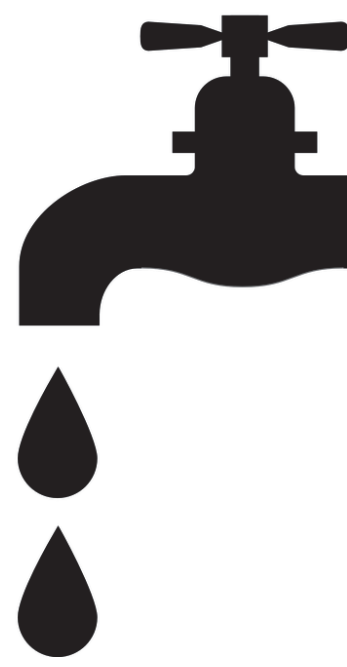
la ONU sobre la biodiversidad biológica celebrada en marzo de 2006 en Curitiba, Brasil, relevaba la importancia que el Medio ambiente y la biodiversidad tienen para el mundo desde la conferencia de Rio de Janeiro de 1992 (El Sol de Zacatecas, "Un mundo en cambio"; 2006). En aquel entonces se trató de ver la relación entre desarrollo y medio ambiente, oficializándose la expresión desarrollo sostenible. Pero pasaron más de diez años y se constató que, prácticamente, todos los indicadores ambientales habían empeorado puesto que la lógica de ese tipo de desarrollo lleva consigo la devastación ecológica y la creación de mayores desigualdades sociales. Hoy se considera al cambio climático como fenómeno que puede llevar a la extinción de la vida y en esta ocasión, junto con el hombre, está condenada a desaparecer una proporción importante de las especies que pueblan el planeta.

Guerras, crimen organizado, avance de la desertificación en inmensas regiones del planeta y otros fenómenos igualmente graves y devastadores siguen llevando a poblaciones enteras del mundo a migrar hacia lugares donde esperan que el ambiente natural y humano les resulte más favorable para la conservación de la vida. Pero, Estados Unidos, al comprobar el crecimiento de la

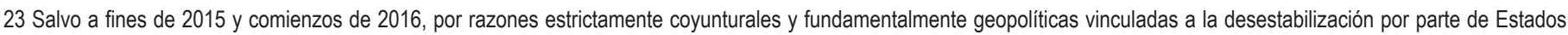
Unidos del gobierno chavista de Venezuela y para contrarrestar la fuerza política del liderazgo de Putin, el Presidente de Rusia, país que es el mayor proveedor de petróleo y gas en Europa.

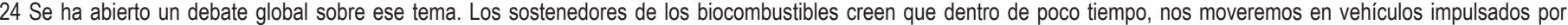
derivados de aceite de soja, girasol, alcohol de maíz o caña de azúcar.

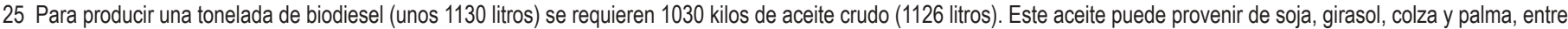
otros cultivos.

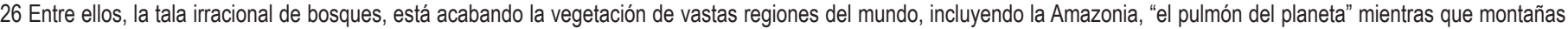
de basura siguen creándose alrededor de las ciudades, muchas de las cuales terminan por precipitarse al mar. Por otra parte, la exploración de petróleo en los océanos y los desbordamientos de oro negro contaminan las reservas marinas. Un sinfín de problemas de distinto orden, relacionados con la organización capitalista del mundo, siguen intactos; peor aún, continúan incrementándose de día en día, en forma acelerada. 


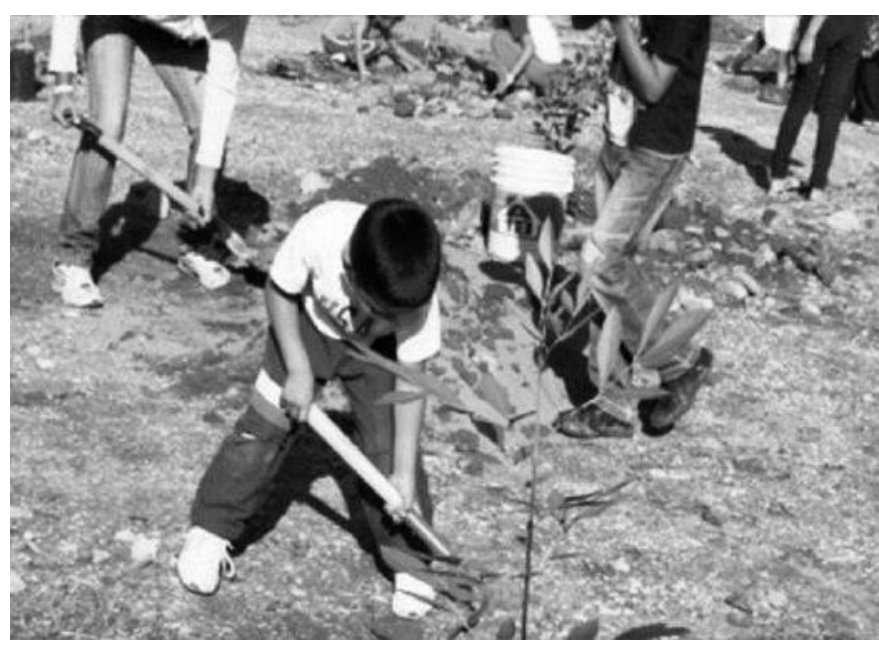

inmigración masiva de personas que llegaban desde el Sur, se propuso impedir la extensión de un fenómeno que los sectores conservadores consideran como invasión extrajera. A mediados de los años 90, comenzó a construir en la frontera de más de 3000 kilómetros que comparte con México, barreras de seguridad de alta tecnología.

Detener la inmigración ilegal se volvió una cuestión política de alto interés para los partidos políticos, a pesar de que ese fenómeno existe desde mucho tiempo antes y sin que se tome en cuenta el aporte que los migrantes realizan para contribuir al desarrollo económico, social y cultural de ese país. Ahora es de público conocimiento el calvario que esos migrantes deben sufrir al recorrer México. Por el camino, caravanas de hombres, mujeres y niños son asaltadas por policías, bandas de narco-traficantes y delincuentes comunes. Se los retiene como esclavos, se chantajea a sus familias pobres que viven en países lejanos para que paguen su rescate y si eso no se puede conseguir, se los obliga a ingresar como sicarios al crimen organizado.

En caso de fallar ambas opciones se les tortura y mata como ocurrió en San Fernando, Tamaulipas, donde 72 migrantes fueron ejecutados luego de sufrir toda clase de afrentas a su dignidad de personas humanas. $\mathrm{Y}$ aquellos afortunados que logran transitar con vida por México, luego de iniciar su camino montados en el tren llamado "La Bestia" y pueden escapar o huir de sus persecutores a lo largo de esa odisea, burlando celadas tendidas por delincuentes, policías o miembros del ejército, caen con facilidad en manos de "Coyotes" que les "ayudan" a pasar la frontera norteamericana a cambio de gruesas sumas de dinero, luego de hacerles sufrir, ellos también, nuevamente, toda clase de vejámenes.

A los migrantes, cuando están por fin del otro lado de las líneas fronterizas les toca enfrentar los Guardias de Estados Unidos y organizaciones armadas de ciudadanos norteamericanos ideológicamente fascistas, racistas, xenófobos, que los persiguen, cazan como a animales y tratan como invasores y delincuentes. Sobre ellos, con toda impunidad, ejercen formas aberrantes de violencias injustas e inútiles. El aumento en flecha de la población replantea esa problemática cuando empiezan a escasear los alimentos básicos y la población crece a un ritmo alarmante, especialmente en zonas urbanas, con grandes complicaciones nutricionales.

Por otra parte, aunque han variadolas condiciones nutricionales y se redujo drásticamente la necesidad de energía debido a la difusión del transporte automotriz y un estilo de vida mucho más sedentario que en el pasado, haciendo que las personas disminuyan paulatinamente lo que ingieren y haciendo que la necesidad de comida se comprima, ello no llega hasta más allá de cierto punto ${ }^{27}$. Además, dentro de 30, 40 o 50 años, cuando habrá que vivir sin petróleo, fuente de energía no renovable que moldeó la historia del siglo XX hizo que su fin inexorable disparase una carrera contra el tiempo en la búsqueda de sustitutos para el "oro negro"(J. Rodríguez Anido, La Feria de las Maravillas; 2008).

Frente a problemáticas tan complejas, a la finitud del mundo (Jacquard, Albert/Jacques Lacarrière;

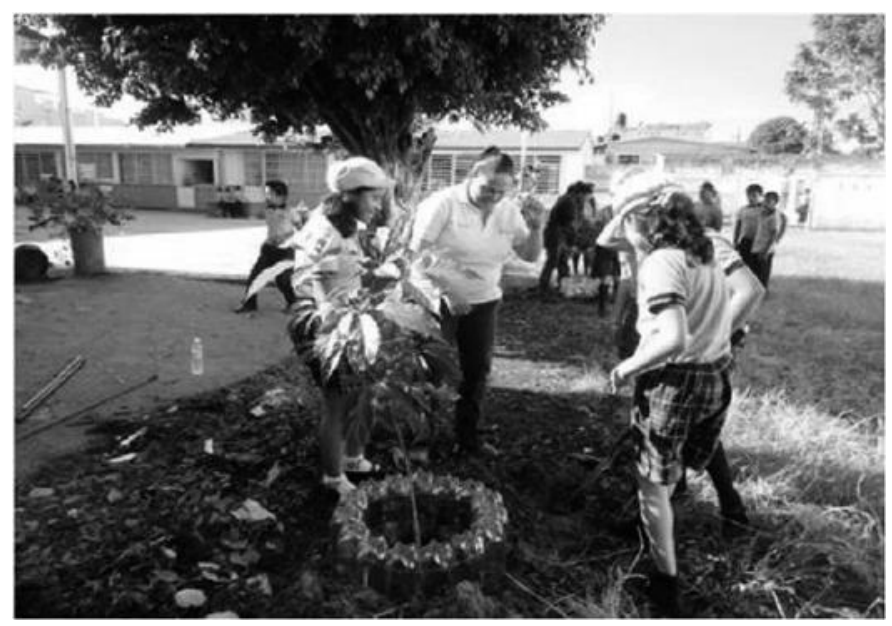

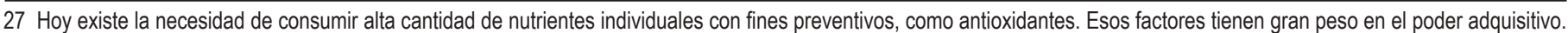
Cuando mejoran las condiciones económicas, la gente consume más carne. 
Sciences et Croyances; 1999) y al caos en que este se encuentra (Ramonet, Ignacio, Géopolitique du chaos; 1999, los proyectos de desarrollo humano tienen una palabra sumamente importante por decir.

\section{Referencias bibliográficas}

- Allègre, Claude (2009): La science est le défi du XXIème. Siècle. Ed. Plon, Paris, Francia.

- Arriola, Q. G. (2007): Desarrollo Humano: Introducción conceptual, Guatemala.: Argrafic.

- Banco Mundial, (2003): Desigualdad en América Latina y el Caribe: ruptura con la historia, Washington DC.

- Beltrán Gaos, Mónica (2004) “Tolerancia y derechos humanos". Política y cultura, Primavera, Núm. 21.

- Carlos, J. (2012): Educación y Justicia Social en América Latina. Universidad Nacional de San Martín. Primera Edición, Buenos Aires.

- Calderón, F. (1999) (Asesor del Programa de las Naciones Unidas para el Desarrollo, PNUD), Bolivia. La Nueva Cuestión Social bajo la Mirada del Desarrollo Humano, Bilbao (España); Calderón, F. (2007):Ciudadanía y Desarrollo Humano.Argentina: Siglo veintiuno editores.

- Canales, 2006. "Desarrollo humano y capacidades. Aplicaciones teoría de las capacidades de Amartya Sen a la educación". Revista española de pedagogía; Calderón, F, Alicia Szmukler. (1997):"La pobreza y las nuevas condiciones de desigualdad social". Nueva Sociedad 166, N.149; Calderón, F.,y Lechner N. (1996) Modernización y gobernabilidad democrática. Informe para el Programa de Naciones Unidas para el Desarrollo. PNUD.

- Castillo, Nydia. (2014): Cultura de Paz. Universidad Politécnica de Nicaragua. Volumen 20. Managua, Nicaragua; Castillo, N. (2011):"Políticas Públicas, Educación Superior y Atención a la Discapacidad". Educación y Sociedad Siglo XXI.

- Cejudo (2007):“El objetivo de la educación, como piensa otra teórica del enfoque de las capacidades, Martha Nussbaum; Cejudo CR., (2006):“Desarrollo humano y capacidades. Aplicaciones de la teoría de las capacidades de Amartya Sen a la educación". España, Rep(Revista española de pedagogía), año LXIL.

- CEPAL, (2013): Programa de Naciones Unidas para el Desarrollo, informe. Coraggio, José Luis (1994) trabajo en el III Seminario Internacional “Educación Popular y Universidad", Joao Pessoa, Brasil.

- Del Percio, E., (2010): La condición social: consumo, poder y representación en el capitalismo tardío. Segunda Edición, Buenos Aires: Jorge Baudino Ediciones.

- Escotet, Miguel Angel:"La universidad ante el siglo de la incertidumbre", in: Julio Rodríguez Anido (compilador), Educación Superior, Desarrollo y Globalización, Desafíos del Tercer Milenio, Ed. Gobierno del Estado de Zacatecas y Universidad Autónoma de Zacatecas, México.

- Molerio, Pérez Osana: "Aprendizaje y desarrollo humano", Revista Iberoamericana de Educación, No. 44, Cuba, 2007.

- Nussbaum, 1997, citado en Cejudo, R. (2006). “Desarrollo humano y capacidades. Aplicación de la teoría de las capacidades de Amartya Sen a la educación". Revista Española de Pedagogía.

- Ornelas Delgado, Jaime (2008): Hacia una Teoría Latinoamericana del Desarrollo, Universidad Autónoma de México.

- Jacquard, Albert/Jacques Lacarrière (1999): Sciences et Croyances, Espaces Libres, Ed. Albin Michel, Paris, Francia.

- Molerio, P. O., Otero, R. I., y Nieves, A. Z. (2007, 24 de Octubre). "Aprendizaje y desarrollo humano". Iberoamericana de educación. http://www.rieoei. org/deloslectores/1901Perez.pdf.

- Ornelas Delgado, Jaime(2008):Hacia una Teoría Latinoamericana del Desarrollo, Universidad Autónoma de México.

- Preciado C. A. (2011):"Entre el Consenso de Washington y el Consenso de Beijing", Ixaya, México.

- Ramonet, Ignacio (1999): Géopolitique du chaos, Col. Folio/actuel, Ed. Gallimarad, Paris, Francia.

- PNUD. (2012): El Índice de Desarrollo Humano en México: cambios metodológicos e información para las entidades federativas. México. Offset Santiago; PNUD (1990): Informe sobre el desarrollo humano (Madrid, Mundiprensa); PNUD (1996): Programa de Naciones Unidas para el Desarrollo; PNUD (2004): Informe sobre el desarrollo humano (Madrid, Mundiprensa) (El primer capítulo fue redactado por Sen, A.), citado por Cejudo, R. 2006;PNUD (2009):Informe sobre desarrollo humano. Superando barreras: Movilidad y desarrollo humano. Nueva York; PNUD (2015): “La revolución digital deber 
ser una revolución del desarrollo", Mensaje de la Comisión de la Banda Ancha de las Naciones Unidas, PNUD, 2012.Programa de Naciones Unidas para el Desarrollo. Informe.

- Proust, Dominique: "Où se cache la vie dans l'Univers? » Entrevista efectuada al astrónomo francés por la periodista Pauline Gravel, in Le Devoir, Montreal, Quebec, Canadá, 04.02.09.

- Rifkin, J.(1996):El fin del trabajo. Nuevas tecnologías contra puestos de trabajo: el nacimiento de una nueva era. Paidós, Barcelona.

- Rodríguez Anido, Julio (2009): La Feria de las Maravillas, Ed. UAZ, COZCYT, Zacatecas, México.

- Sachs (1999), en Calderón, Fernando (2007): "Ciudadanía y Desarrollo Humano", Ed. Siglo XXI Argentina.

- Sen, Amartya (1999): Desarrollo y Libertad, Ed. Planeta; Sen, Amartya (2010): La idea de la justicia. Ed. Taurus, Madrid; Sen, Amartya (1997:Bienestar, justicia y mercado. Madrid: Paidós; Sen, A. (1997): Nuevo Examen de la Desigualdad Alianza Economía

- Stéphanie Bonvicini y Jacques Attali (2009) : Le sens des choses, Ed. Robert Laffont, S.A. Paris, Francia.

- Stiglitz, Joseph E. (2014): La creación de la sociedad del aprendizaje. Ed. Crítica, M.R., México DF; Stiglitz, Joseph E. (2015): El precio de la desigualdad, Ed. Taurus, México DF.

- Szmukler A. (1997): La Pobreza y las Nuevas condiciones de Desigualdad Social. Universidad Católica Boliviana, La Paz.

- Tedesco, J. (2000): Educar en la sociedad del conocimiento. Conocimiento y sociedad. Segunda Edición Buenos Aires: Fondo de Cultura Económica; Tedesco, J. (2009): Educar en la Sociedad del Conocimiento. Artes Gráficas del Sur. Buenos Aires Argentina; Tedesco, J. (2001): Educación y justicia social en América Latina. Buenos Aires, Argentina: Fondo de Cultura Económica.

- Tejeda, J. L. (2004): La línea, de la Frontera y la modernidad. Estudios Fronterizos; Tejeda. J. (2003): "Ciudadanía, derechos sociales y multiculturalismo" en La democracia y los ciudadanos, de García Flores R. Universidad Autónoma Metropolitana. México.

- UNESCO (1998): Conferencia Mundial sobre la Educación Superior en el siglo XXI. Visión y acción y marco de acción prioritaria para el cambio y el desarrollo de la educación Superior, Paris, Francia. 